\title{
Objective Measurement of Effective Message through Photograph among the Public
}

\author{
Adzrool Idzwan Hj. Ismail, Kamarudzaman Md. Isa, Mustaffa Halabi Hj. Azahari \\ \& Roziah Mohd Janor
}

Faculty of Art \& Design \& Academic Quality Assurance Department, University Technology MARA, 40450 Shah Alam, Selangor Darul Ehsan, Malaysia

Email: adzrool@yahoo.com

\begin{abstract}
Photograph' is to an extent very close with visual representation, which consists as a part of an act of seeing which establishes places and subject matters in the surrounding world. These would in part, described in words and explained such paradigm. However, it's still yet lacking in the content of the emotional experience as a total. Such form of images plays as an important role, yet lacking realization, as it is also a part of a design committee in society. The act of seeing which establishes our place in the surrounding world, we can describe the world using words, but words can never describe the emotional experience in total. What does visual really mean? How is visual measured? As an observer, how can we define whether the message and the meaning of a particular visual is delivered and understood along with the information it carries? Those three questions play important roles especially with the rapid growth of technology, which contributes to the development of human knowledge especially in the art industries. This paper explores the problems in understanding of photography imageries and their impact to the society.
\end{abstract}

Keywords: effectiveness; message; measurement; photography; visual image.

\section{$1 \quad$ Introduction}

'Seeing comes before words', says John Berger [1]. And he continues with:

"But there is also another sense in which seeing comes before words. It is seeing which establishes our place in the surrounding world; we explain this world with words, but words can never undo the fact that we are surrounded by it." [1]

Photography is the prevailing appearance of enduring image in the human race. A.A. Berger [2] defined photograph as an image in the shape of a positive print, taken by a camera (a device with a lens and a shutter) and reproduced, permanently, on a photosensitive surface. Photographs are used for many reasons, from capturing a wedding ceremony to documenting historical events

Received May $17^{\text {th }}, 2009$, Revised October $29^{\text {th }}, 2013$, Accepted for publication November $8^{\text {th }}, 2013$

Copyright (C) 2013 Published by LPPM ITB, ISSN: 1978-3078, DOI: 10.5614/itbj.vad.2013.4.2.4 
in newspapers. It is so obvious why most of us would believe that cameras do not lie, and pictures or photographs worth one thousand words [3].

For that, the viewers might have the feelings that whatever they see is a perfect representation of authenticity, but of course, photographic images are subjective interpretations of events.

We often see picture or photography as an adjunct to a written story or story line. But, in this situation picture is certainly the main attraction to impress viewers at the first glance compare to text or writing through a reading process. Pictures are also able to communicate the message effectively and compared to writings and reading process. Pictures are indeed, capable to communicate with people who really observe. It is important to convey ideas through pictures that express basic human values, which have emotions, belief, traditions, and knowledge that we share as a human being [3].

What does visual really mean? How is visual measured? As an observer, how can we define whether the message and the meaning of a particular visual is delivered and understood along with the information it carries? Those three questions play important roles especially with the rapid growth of technology, which contributes to the development of human knowledge especially in the art industries.

\section{Literature Review}

\subsection{Photography and the Six Perspectives}

According to Paul Martin Lester [4], photography runs the gamut from simple amateur snapshots to enormously expensive professional enterprises. In art perspective, artist uses images to express their inner emotions, photojournalist to illustrate the people's life in the news, commercial photographers to sell products and ideas, and scientist to make an unseen world visible. In 1827, photography has become the world's most popular medium for creating visual messages in terms of actual users.

The six-perspective mention by Paul Martin Lester [4] is personal perspective, historical perspective, technical perspective, ethical perspective, culture perspective and critical perspective.

\subsection{Photography as a Window of Realistic}

According to the "Persuasion in The Media Age" by Timothy A. Borchers, Messaris argues that one of major function of images is to represent the reality [5]. Images will show to the society the truth and realty in our daily life. This is 
because, the image is an iconic properties. Definition of "realistic " is - aware or expressing awareness of things as they really are; "a realistic description"; "a realistic view of the possibilities"; "a realistic appraisal of our chances". In this case, when the word (realistic) is applied in photography, it presents the real situation that happens and been captured during that moment.

We refer back to the definitions of photography by Liz Well [6]; photography"is a particular sort of image, one which operates through freezing a moment in time portraying object, people and place as they appeared within the view of the camera at that moment. It contributes to the dislocation of time and space, enlightening and enlivening history and geography. As such, it has attracted scrutiny from philosophers concerned with its semiotic structure and its phenomenological impact". Referring to this definition, we can highlight that photography is actually dealing with actual [3].

\subsection{Photography as a Mirror of Interpretive}

Images especially photography needs a process of interpreting. This is because all photograph demands interpretation in order to be fully understood and appreciated. According to Barrett [3], when we look at photograph, we tend to think of them as 'innocent', that is as bare fact, as direct surrogates of reality, as substitutes for real things, as direct reflections. However Ernst Gombrich [7] in his book 'Art and Illusion' said that is no such things as an innocent eye. The world cannot be seen and the same time, we ignore our prior experience in and knowledge of the world. One western philosopher, Nelson Goodman said:

"As Ernst Gombrich insists, there is no innocent eye. The eye comes always ancient to its work. Obsessed by it's past and by old and new insinuations of the ear, nose, tongue, fingers, heart, and brain. It functions not as an instrument self-powered and alone, but as a dutiful member of a complex and capricious organism. Not only how but what it sees is regulated by need and prejudice" [8].

As a respond to the statement, Barrett said, there is no such thing as the innocent camera [3]. What Goodman says of the eye is true of the camera, the photograph, and the 'photographer eye' as well:

"It selects, rejects, organizes, discriminates, associates, classified, analyzes, and constructs. It does not so much mirror as take and make; and what it takes and makes it sees not bare, as items without attributes, but as things, as food, as people, as enemies, as stars, as weapons". 
Barrett also said every photograph need to be interpreted. They are not innocent and devoid of prejudices, nor are they simple mirror images. According to him, they are made, taken and constructed by skilful artists and deserve to be read, explained, analyzed and deconstructed [3].

Definition of interpretation is whenever attention and discussion move beyond offering information to matter of meaning. Hans-Georg Gadamer, quoted by Klaus Davi in Art and Philosophy, said to interpret is "to give voice to sign that don't speak on their own" [3]. It also to account for all the described aspect of a photograph and to posit meaningful relationships between the aspects. The process of interpreting photograph is a process of telling someone else, in speech or in writing, what one understands about a photograph. To complete this process the viewer must ask these questions - "what one thinks a photograph is about?"

Basic knowledge of interpreting a photograph is about telling the meaning, the point of the photograph, the sense, the tone, or mood of the photograph. Interpretations are more then a single or few sentence statements quoted earlier [3]. Any statement is claims in need of arguments, or hypotheses in need of convincing body of evidence (see Figure 1).

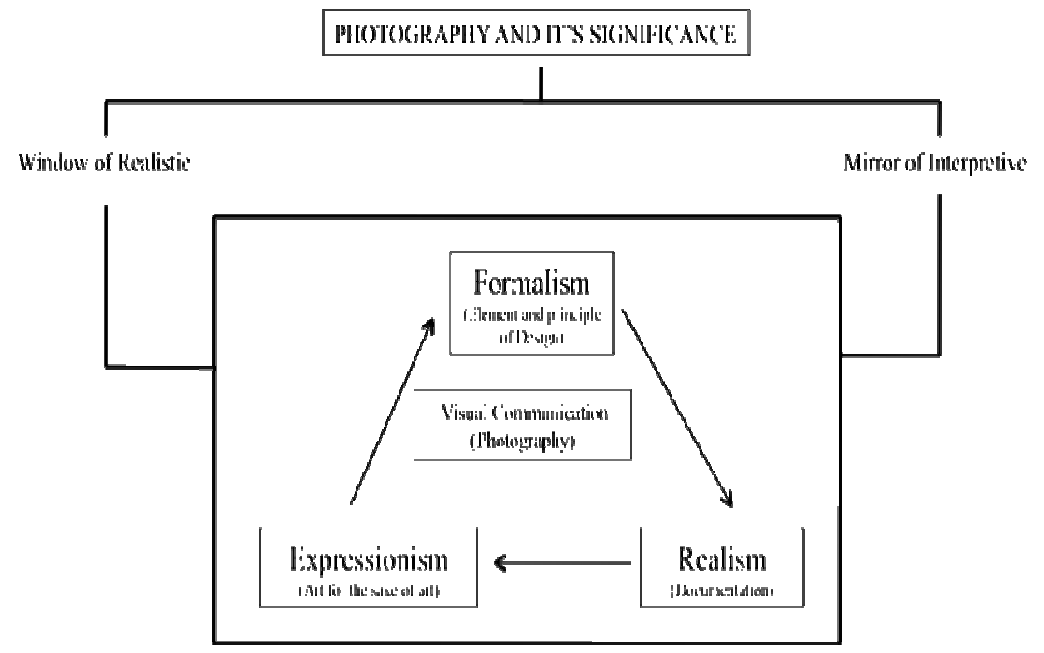

Figure 1 The structure of photography and it's significance.

\section{$3 \quad$ Methodology}

This part will discuss and focuses on methodology in the way to conduct this research process. The first step is to ensure the efficiency of the process. The 
first step is, the research design and rational of selection will be based on Dick, Carey and Carey's instructional model. Meanwhile the model of theories sensual and perceptual process will be use as a guide to develop the research instrument (questionnaire): and research methodology is developed based on qualitative and quantitative research design.

This research is about the objective measurement of effective message through photograph among the public. In order to integrate the theories of sensual and perceptual process, two different approaches have been developed, which subjective approach and objective approach in order to prepare the effective instrument to achieve the aims and objective of this research.

The main objective of this research is to establish the aspect of image making that is measurable and to design the guideline for image-maker to producing a good and effective image based on what audience need. This research also aims to identify what is the value that should be in an effective image in order to attract and give good impact to the viewer.

\section{$4 \quad$ Theoretical Framework}

Based on Literature review, the operational theoretical framework for this research (Objective Measurement of Effective Message through Photograph Among the Public) is according to the sensual perception theories of visual communication and also, the theories from Paul Martin Lester [4], A.A. Berger [2] and lastly Paul Messaris [9]:

Lester (2003:30), - "human brain will respond to the four major attributes on the viewed object; color, form (dots, lines, shapes), depth (space, size, perspective) and movement".

Berger (1998:69), - "Factor such as a line, shape, dimension, lighting, design, spatiality, color, and perspective all can be looked at as conveying 'message' or being kings of sign information that have an impact us"

Messaris (1997:3) - “... through combinations of lines and shapes and colors on a piece of paper or a movie screen or a video monitor, pictures are able to recreate the kinds of visual information that our eyes and brains make use of when we look at the real world" 


\section{$5 \quad$ Measures, Metrics and Model}

The Image Quality is defined by Technology Variables, System Models, Physical Image Parameters, Visual Algorithms, Customer Perceptions, Image Quality Models, and Customer Quality Preference (see Figure 2).

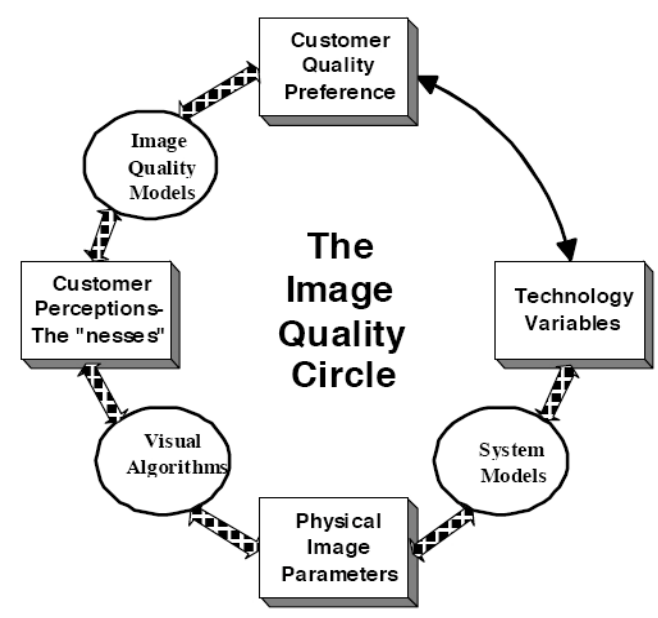

Figure 2 "The Image Quality Circle", by Engeldrum, Peter G. [10-11].

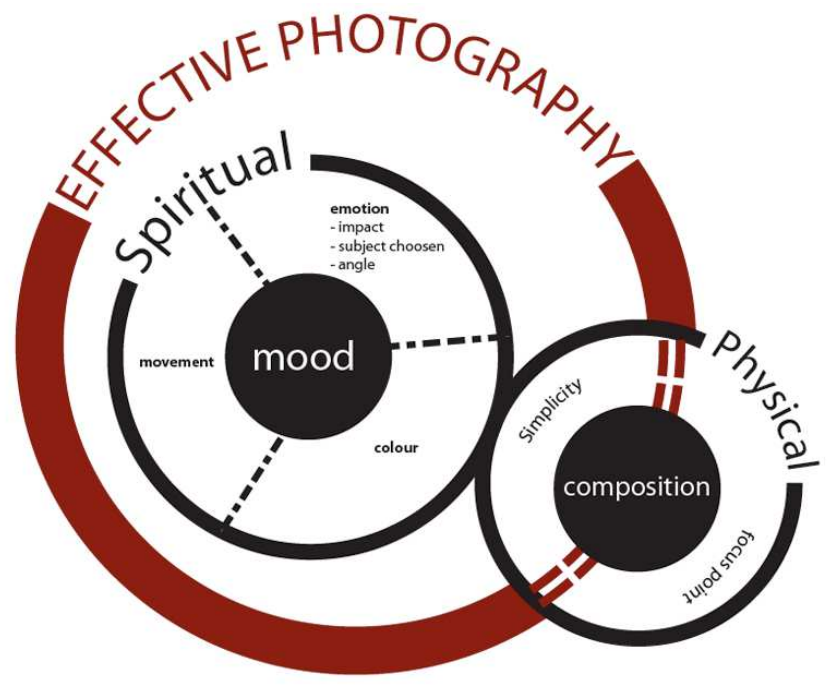

Figure 3 "The Effective Photography Diagram". 
The Effective Photography is defined by two factors: Spiritual and Physical. The Spiritual factor includes color, movement and emotion (impact, subject chosen, angle); all of which are centered to Mood. The Physical factor includes focus point and simplicity, which are centered to Composition (see Figure 3).

Approach in developing process (according to Figures 2 and 3):

Multiple Regression Formula:

$$
\begin{aligned}
& (\mathrm{DV}) \mathrm{Y}=b 0+b 1 X 1+b 2 X 2 \\
& \text { Mood }=\boldsymbol{b} 0+\boldsymbol{b} 1(\text { emotion })+\boldsymbol{b} 2(\text { colour })+\boldsymbol{b 3}(\text { movement }) \\
& \text { Composition }=\boldsymbol{c} 0+\boldsymbol{c} 1 \text { (simplicity) }+\boldsymbol{c} 2(\text { Focus Point })
\end{aligned}
$$

\section{Conclusion}

Although this kind of research has long been conducted, there is still room for improvement identified. This shows that proper emphasis must be placed and the continuity of the research in relation to image, the society and its comprehension must be prominent especially in education and the real-life. It is due to the fast pace of the modern technology that allows image to become a medium in an effective communication.

Taking that into consideration, there is still a lot of hard work to be done because in the future, an image may become the main medium of education. The establishment of a perfect civilisation with good values is determined by the image they see.

From this research, the findings show that the effectiveness of an image can be measured from two different aspects; physical and spiritual.

\section{References}

[1] Berger, J. 1972. Ways of Seeing, London: BBC/Penguin.

[2] Berger, A.A. 1998. Seeing is Believing-An Introduction to Visual Communication, $2^{\text {nd }}$ Ed., Mauntain View, Mayfield Publishing Company.

[3] Barrett, T. 2000. Criticizing Photographs, an Introduction to Understanding Images, $3^{\text {rd }} \mathrm{Ed}$.

[4] Lester, P.M. 2003. Visual Communication, Images with Message, $3^{\text {rd }}$ Ed., United States, Thomson Wadsworth.

[5] Borchers, T.A. 2005. Persuasion in the Media Age, $2^{\text {nd }}$ Ed., New York: McGraw Hill.

[6] Wells, L. 2003. The Photography Reader, $1^{\text {st }}$ Ed., New York, Routledge. 
[7] Gombrich, E.H. 1960. Art and Illusion, A Study in The Psychology of Pictorial Representation, Phaidon, Oxford/London.

[8] Goodman, N. 1976. Languages of Art: An Approach to A Theory of Symbols, Indianapolis, Hackett Pub. Co.

[9] Messaris, P. 1997. Visual Persuasion: The Role of Images in Advertising, London: Sage.

[10] Engeldrum, P.G. 1989. A New Approach to Image Quality, Presented at the IS \& T 42nd Annual Meeting, May $14^{\text {th }}, 1989$, Paper Summaries, $p$. 461.

[11] Engeldrum, P.G. 1990. Measuring Customer Perception of Print Quality, TAPPI Jour., 73(3), p. 161. 